\title{
MÉTODO DE FORMAÇÃO POLÍTICA DA ESCOLA NACIONAL FLORESTAN FERNANDES DO MST
}

\author{
MÉTODO DE FORMACIÓN POLÍTICA DE LA ESCUELA NACIONAL FLORESTAN \\ FERNANDES DEL MST
}

\section{METHOD OF POLITICAL TRAINING OF THE FLORESTAN NATIONAL SCHOOL FERNANDES TO THE LANDLESS WORKERS MOVEMENT IN BRAZIL}

\author{
DOI: http://dx.doi.org/10.9771/gmed.v1111.29832
}

\author{
Alessandro Santos Mariano ${ }^{1}$ \\ José Claudinei Lombardi ${ }^{2}$
}

\begin{abstract}
Resumo: O objetivo deste artigo é refletir sobre o método de formação política Escola Nacional Florestan Fernandes, uma escola coordenada pelo Movimento dos Trabalhadores Rurais Sem Terra e que tem como principal papel a formação de militantes de movimentos e organizações populares do Brasil e outros países. A ENFF assume a concepção marxista de construção e socialização do conhecimento (MARX, 1987) e a orientação pedagógica da Pedagogia Socialista (PISTRAK, 2009), da Educação Popular (FREIRE, 2005 e da Pedagogia do Movimento (CALDART, 2004). Essa perspectiva pedagógica referencia-se no trabalho como princípio educativo, como práxis que articula a prática com o estudo, em organicidade com a arte e a cultura. A ENFF adota uma perspectiva contra hegemônico, direcionando seu trabalho para a formação da consciência de classe, por meio da socialização de conhecimentos de filosofia, de história e economia de política, considerados necessários para a formação crítica de sujeitos sociais que atuam com vistas à transformação revolucionária da sociedade, superando o capitalismo e avançando em direção ao socialismo, entendendo este como uma fase de transição para o comunismo.
\end{abstract}

Palavras-Chave: Formação Política, Consciência de classe, MST, Pedagogia Socialista.

Resumen: El objetivo de este artículo es reflexionar sobre el método de formación política de la Escuela Nacional Florestan Fernandes, una escuela coordinada por el Movimiento de los Trabajadores Rurales Sin Tierra y que tiene como principal papel la formación de militantes de movimientos y organizaciones populares de Brasil y otros países. La ENFF asume la concepción marxista de construcción y socialización del conocimiento (MARX, 1987) y la orientación pedagógica de la Pedagogía Socialista (PISTRAK, 2009), de la Educación Popular (FREIRE, 2005 y de la Pedagogía del Movimiento (CALDART, 2004). en el sentido de que el hombre no es un ser humano, sino un ser humano, un ser humano, un ser humano, un ser humano, un ser humano y un ser humano. de la socialización de conocimientos de filosofía, de historia y economía de política, considerados necesarios para la formación crítica de sujetos sociales que actúan con miras a la transformación revolucionaria de la sociedad, superando el capitalismo y avanzando hacia el socialismo, entendiendo éste como una fase de transición para el comunismo.

Palabras clave: Formación política, Conciencia de clase, MST, Pedagogía Socialista.

Abstract: The objective of this article is to reflect on the method of political formation National School Florestan Fernandes, a school coordinated by the Movement of Landless Rural Workers and whose main role is the formation of militants of movements and popular organizations of Brazil and other countries. The ENFF assumes the Marxist conception of the construction and socialization of knowledge (MARX, 1987) and the pedagogical orientation of Socialist Pedagogy (PISTRAK, 2009), Popular Education (FREIRE, 2005) and Pedagogy of Movement (CALDART, 2004). Pedagogy is referred to in the work as an educational principle, as a praxis that articulates the practice with the study, in organicity with the art and the culture. The ENFF adopts an anti-hegemonic perspective, directing its work towards the formation of the class consciousness, through of socialization of knowledge of philosophy, of history and of political economy, considered necessary for the critical formation of social subjects who work with a view to the revolutionary transformation of society, overcoming capitalism and moving towards socialism, understanding this as a phase of transition for communism. 
Keywords: Political Formation, Class Consciousness, MST, Socialist Pedagogy.

\section{Introdução}

O presente artigo tem por objetivo refletir sobre o método de formação política da Escola Nacional Florestan Fernandes (ENFF), um centro de educação e formação autônomo da classe trabalhadora, coordenado pelo Movimento dos Trabalhadores Rurais Sem Terra (MST) e que constitui-se em um espaço para a socialização de conhecimentos e experiências, na perspectiva de articulação entre teoria e prática, visando fortalecer a luta e organização da classe trabalhadora mundial, numa perspectiva internacionalista 3 .

Este estudo é resultado de uma pesquisa desenvolvida no período entre 2017 e 2018, que consistiu em investigar a e analisar a proposta pedagógica e prática formativa da Escola Nacional Florestan Fernandes, que se fundamentam nas teorias e práticas pedagógicas sistematizadas na longa história de luta da classe trabalhadora, a saber: a Pedagogia Socialista (PISTRAK, 2009), a Educação Popular (FREIRE, 2005) e a Pedagogia do Movimento (CARDART, 2004). Essas teorias e práticas se sustentam no trabalho como princípio educativo, fornecendo as balizas necessárias à formação crítica dos trabalhadores.

A Pedagogia Socialista é o conjunto histórico dos esforços teóricos e práticos de educação dos trabalhadores (as) na direção de transformar radicalmente a sociedade capitalista e construir uma nova ordem social hegemonizada pelos trabalhadores. Nessa pedagogia o trabalho é a matriz formativa principal, derivando desta a auto-organização, a coletividade e o estudo das contradições da realidade como elementos centrais na formação da classe trabalhadora (PISTRAK, 2009). A Educação Popular foi forjada nas experiências educativas populares do Brasil e América Latina, tendo como base a Pedagogia do Oprimido de Paulo Freire (FREIRE, 2005). A Pedagogia do Movimento constitui uma síntese que o MST sistematizou ao longo do processo de organização popular dos Sem Terra, de luta pela reforma agrária e sua relação com a formação da consciência de classe desses trabalhadores (CALDART, 2004).

No processo de formação da consciência "a passagem do senso comum à consciência filosófica é condição necessária para situar a educação numa perspectiva revolucionária” (SAVIANI, 1983, p. 13), Nesse sentido, a ENFF busca socializar o conhecimento estratégico vinculado a luta pela emancipação humana, que tem como base o saber clássico da filosofia, história e economia política, considerando a pluralidade da tradição marxista desde os diversos continentes, compreendendo as a especificidade e desafios da materialidade da luta de classes.

A ENFF é localizada no município de Guararema, a 60 quilômetros da cidade de São Paulo. Foi inaugurada em janeiro de 2005, sendo resultado da união dos trabalhadores(as) que, durante cinco anos (2000 a 2005), se mobilizaram para a construção de um projeto que não se reduz à estrutura física (Pizetta, 2007, p.2), mas da construção de uma escola “de formação de militantes, dirigentes, formadores dos movimentos e organizações sociais/populares, do campo e da cidade, da América Latina e de outros continentes". 


\section{Método Pedagógico e as dimensões formativas}

O método formativo da ENFF é organizado tendo por fundamento as conexões fundamentais da constituição histórica do ser humano: a vida produtiva (o trabalho para a produção das condições materiais de existência), a luta social pela organização coletiva, cultural e histórica, assumindo a concepção marxista por meio do qual buscar-se articular quatro dimensões para a formação humana e que sustentam e orientam a práxis pedagógica da ENFF, sendo elas: o trabalho, o estudo, a organização, a cultura e a arte. (ENFF, 2018)

A dimensão formativa através do trabalho é considerada como um dos pilares do projeto educativo da escola, pressupondo-se que que e por meio do trabalho que os seres humanos se fazem homens. No atual modo de produção societário, podemos afirmar que o trabalho não se configura como possibilidade de liberdade daqueles que dele se fazem enquanto o fazem; ao contrário, se configura como grande expressão de exploração e de apropriação privada de poucos (burguesia/capitalistas) do trabalho que outros (trabalhadores) produzem. Ou seja, o capital se configura como uma relação social de expropriação e exploração. É contra essa lógica que a classe trabalhadora luta.

Todos os estudantes que passam pela ENFF, desenvolvem trabalho prático (trabalho doméstico, agrícola...), pois considera-se que por meio dele os educandos(as) se identificam como classe trabalhadora. Para isso, a Escola não dispõe de funcionários, sendo todo o processo de gestão, de organização e de atividades meios e fins coletivo e auto organizado pelos estudantes e militantes que vivem na ENFF. A atividade que se realiza é o "trabalho socialmente útil” (PISTRAK,2009), sendo todo o processo de produção e a apropriação dos resultados feitos de forma coletiva, contrapondo-se à apropriação privada que é a lógica do sistema capitalista.

A escola tem organizado o seu processo de gestão do trabalho a partir de Setores e Unidades de Trabalho. Por exemplo: o Setor de Produção engloba horta, viveiro, animais, pomar e outras unidades; o Setor Pedagógico compreende a ciranda infantil, a cultura, a memória etc.; o Setor de Serviços é dividido em restaurante, limpeza geral, manutenção e outras. Trata-se de um processo de trabalho que envolve planejamento e avaliação permanente. $\mathrm{O}$ trabalho é realizado de forma coletivo e cada estudante compõe uma unidade de trabalho que atua por $1 \mathrm{~h} 30 \mathrm{~min}$ de trabalho diariamente. Todo o planejamento é feito pelos estudantes, com o acompanhamento de um militante responsável pela unidade de trabalho. (ENFF, 2017)

Com relação a dimensão do Estudo, a ENFF objetiva um conjunto de práticas e espaços formativos desde aulas com aporte de educadores(as), momentos de leituras, seminários e grupos de estudos, entre outros, a fim de proporcionar aos militantes um amplo espaço de reflexão dos problemas da existência, em conexão com conhecimentos de filosofia, história, economia política e outros, a fim da apropriação dialética desses conhecimentos como ferramenta do processo de transformação histórica.

Referencia-se no método marxiano de construção do conhecimento, a pressupor a compreensão dos fenômenos e contradições (apreensão empírica e sincrética) da realidade como ponto de partida, as mediações abstratas do pensamento como possibilidade para a superação dessa condição, tendo em vista a 
apreensão concreta da realidade como síntese de múltiplas determinações ou como "rica totalidade das determinações e de relações numerosas" (Marx, 1973).

Nesse sentido, de acordo com Saviani (1984), o estudo organizado deve partir da visão sincrética da realidade (senso comum) e, através de uma reflexão analítica, buscar identificar os vários fatores, as diversas facetas, os múltiplos problemas com que nos defrontamos na nossa realidade existencial, fazendo mediação-análise (apropriação de conhecimentos socialmente construído na humanidade - ciência, filosofia e artes), chegando a uma visão sintética da estrutura dialética da existência humana.

Nesse caminho, o método de estudo desenvolvido na ENFF prima por processos coletivos e individuais, com auxílio de educadores(as), que usam métodos expositivos de transmitir o conteúdo, mas também com atividades auto organizativas pelos estudantes que dispõem de uma estrutura pedagógica, com uma biblioteca com mais de 40 mil exemplares, salas e espaços de estudos individuais e coletivos, também contando com acesso à internet para aprofundamento dos estudos e comunicação.

A dimensão da organicidade, refere-se ao processo de participação permanente de todos na construção de espaços e momentos formativos, organizados em coletivos, forjando assim a coletividade da Escola Nacional. Neste sentido, evidencia-se a seguinte estrutura organizativa, que pode ser compreendida em duas dimensões que se articulam: a Brigada Apolônio de Carvalho e os cursos.

A Brigada Apolônio de Carvalho (BAC) é o núcleo administrativo e pedagógico da ENFF e que tem funções diversas, desde atuação nos setores de trabalho (Horta, recepção, jardim, hospedagem...), sendo organizada em duas grandes frentes: a) os setores de trabalho - dedicados a atividades produtora da vida na ENFF, articulando-se permanente na organização e desenvolvimento do trabalho junto aos cursos e turmas, o que exige: planejamento, divisão de tarefas, estudo e técnicas de desenvolver o trabalho; b) núcleos de base, - que se constituem como o espaço do estudo e aprofundamento político dos processos organizativos da ENFF.

Na BAC também se localiza a Coordenação Política e Pedagógica da ENFF, que é o coletivo de direção política da escola, cuja responsabilidade é coordenar a escola como um todo, acompanhando a BAC, os cursos, bem como em fazer a relação da ENFF com o conjunto do MST e as organizações e movimentos sociais de outros países.

Também integra a brigada o Coletivo de Acompanhamento Político e Pedagógico, que são responsáveis por cada curso, que tem as seguintes funções: a) Planejar e organizar as aulas, temas de estudos; b) fazer o processo de acompanhamento da organicidade, trabalho da turma, no sentido de trazer a dimensão educativa e formativa do processo; e) Fazer diálogos com educadores a fim de contribuir nas definições de metodologia e foco das aulas; f) Atuam como espécie de educadores no cotidiano dos processos de formação em cada turma. (ENFF, 2017)

Os cursos são realizados por núcleos de estudos e por turmas, sendo, em geral, uma turma por ano de cada curso. Em toda turma os estudantes são organizados em Núcleos de Bases (NB's) no sentido da construção de um espaço orgânico de estudo, debate e reflexões em torno do processo do curso e da ENFF. O número de participantes varia de acordo com a quantidade da turma. Cada núcleo deve eleger um coordenador/a e um relator/a. O Coordenador e Coordenadora tem a função de conduzir os 
processos de estudos, bem como representar o núcleo de base na coordenação da turma que é constituída por um representante de cada NB e tem a finalidade de ajudar a conduzir o curso junto com a CAPP (Coletivo de Acompanhamento Político e Pedagógico). O relator, tem a tarefa de garantir a memória (escrita) das atividades realizadas no núcleo de base.

Um outro elemento importante do núcleo de base é a escolha do nome (identidade) do núcleo, que passa por prestar homenagem a um lutador ou lutadora, a um processo histórico de luta ou ainda a dimensões da vida humana expressadas no campo da literatura crítica.

A Cultura e arte é uma das dimensões da formação política, entendida como instrumento para a ação contra hegemônica de classe, em função de fornecer condições (políticas, éticas e estéticas) para que os trabalhadores(as) possam compreender criticamente o que lhes parece natural - desnaturalizar o olhar, os sentidos e os sentimentos para que elucidem que a visão de mundo naturalizada é na verdade a visão de mundo da classe dominante. (ENFF, 2017)

De acordo com Duarte (2016), as artes educam a subjetividade tornando o ser humano capazes de posicionar perante os fenômenos humanos de uma forma que ultrapasse o pragmatismo cotidiano. As artes trazem para a vida de cada pessoa a riqueza resultante da vida de muitas gerações de seres humanos, em formas condensadas, possibilitando que o indivíduo vivencie, de forma artística, aquilo que não seria possível viver com tal riqueza na sua cotidianidade individual.

$\mathrm{Na}$ ENFF, os conhecimentos das artes são socializados através de oficinas especificas para aprender a tocar algum instrumento, desenvolver habilidades das diversas linguagens artísticas (teatro, dança, poesia..), mas também a realização de atividades como noites culturais, sarau de poesias, priorizando a valorização de músicas produzidas nos processos revolucionários ou de critica a sociedade capitalista.

Nesse caminho, na escola realiza atividades chamada de mística, que são espécies de performances artísticas que utilizam as diversas linguagens das artes, para refletir sobre o projeto de humanidade que queremos construir, traduzindo em diversas expressões artísticas o sonho coletivo de uma sociedade socialista, a denúncia do estado de coisa produzido por essa sociedade, e aproximar por meio do sonho humano coletivo o presente do futuro, rememorando as lutas e histórias da classe trabalhadora e projetando a unidade da classe trabalhadora e o processo revolucionário. (ENFF, 2017)

\section{Cursos e o currículo de formação política}

A ENFF, organiza um conjunto de cursos de acordo com as estratégias das organizações e movimentos populares do Brasil e o mundo, anualmente no final de cada ano, realiza-se uma reunião com representantes de organizações mundial, para definirem possíveis ajustes ou criação de novos cursos.

A Escola, organiza os cursos em Núcleos de Estudos (NEs): Teoria Política Nacional; Teoria Política Internacional; Cursos Formais e Sindical popular. O tempo de cada curso varia de uma semana, para cursos de várias etapas, ou etapa única de quarenta e cinco a noventa dias, mas um dos princípios fundamentais do método, é que o curso seja concentrado e também por alternância de tempo, ora na 
ENFF ora nos movimentos e comunidades de origem. Os núcleos de estudos e seus respectivos cursos são:

Núcleo de Teoria Política Nacional, é composto pelos seguintes cursos: a) Introdução Sistemática à obra de Marx; b) Legado Teórico Político de Florestan Fernandes; c) O pensamento de Lênin; d) Curso Nacional Questão Agrária; e) Curso Formação de Dirigentes MST; f) Curso de Formação de Dirigentes dos Movimentos Sociais; g) Feminismo e Marxismo; g) Formação Política para LGBT;

Núcleo Teoria Politica Internacional: a) Formação de brigadas Internacionalistas (Venezuela, palestina, África do Sul, Haiti, Guatemala; b) Curso de Formação de Formadores Latino-americano; c) Curso Conjuntura Internacional; d) Curso Formação de Formadores em Idioma Inglês); e) Curso de Teoria Política Latino-americana.

Núcleo dos cursos formais: a) Mestrado em Desenvolvimento Territorial na América Latina, parceria com a Universidade Estadual de São Paulo (UNESP); b) Mestrado em Saúde, trabalho, ambiente e Movimentos Sociais, parceria com a FIOCRUZ; c) Especialização em Estudos Latino-americanos, parceria com UFJF/ENFF.

Núcleo Sindical popular: a) Formação de Jovens do Sindicado dos Metalúrgicos; b) Formação de Professores da Rede de Ensino Publica; c) Curso de Formação dos Sindicato dos Petroleiros; d) Formação de Formadores do MTD (Movimento dos trabalhadores desempregados); e) Formação de Formadores do MAM (Movimento de Soberania Popular na Mineração).

O currículo dos cursos, tem como núcleo duro as disciplinas de filosofia, história e economia política, sendo ajustado seus focos, conforme a abrangência do curso: nacional, latino americano ou mundial, buscando um compreensão dialética da realidade e construindo conexões com as lutas e os processos históricos revolucionários. Mas, também estuda as teorias e métodos de organização popular, bem como, os temas recortes de classe - gênero, raça, diversidade sexual, temáticas estas, que estão vinculados com os problemas orgânicos, assim como o momento histórico, no qual a teoria e a práxis se aliam para que sejam permanentes a ação e a reflexão ação.

\section{Conclusão}

A ENFF é uma escola de formação da classe trabalhadora, por isso assume a concepção marxista de socialização de conhecimento, primando os conhecimentos de filosofia, história e economia política como base de seu currículo de formação e como princípio educativo o trabalho, estudo e a organização coletiva para a formação de militantes do movimentos sociais, ou seja, desenvolve a formação política e ideológica, entendida como apropriação do conhecimento clássico, aliada à prática e aos desafios das lutas concretas dos movimentos populares da América Latina e do mundo.

Essa escola, cumpre o papel de garantir acesso aos trabalhadores (as) ao conhecimento sistematizado, a fim, de possibilita a compreensão das contradições da sociedade capitalista, e a necessária organização da classe trabalhadora, para lutar e forjar uma sociedade na qual o gênero humano possa tornar efetivas todas suas potencialidades de desenvolvimento livre e universal e, ao mesmo tempo, a vida 
de todos os indivíduos situe-se no mesmo plano de universalidade e liberdade., ou seja a necessária “superação do capitalismo e avance em direção ao socialismo transição ao comunismo”. (DUARTE, 2016, p.102)

Para isso, utiliza métodos pedagógicos que proporcione a apropriação de conhecimentos com exercício prático de outras formas de relação social, com cooperação, divisão de tarefas, solidariedade, na perspectiva do desenvolvimento da consciência de classe. Assim, desenvolve uma formação comprometida com o projeto político de transformação da sociedade, fortalecendo o papel histórico da classe trabalhadora nos processos revolucionários, para a construção de uma sociedade na qual o gênero humano possa tornar efetivas todas suas potencialidades de desenvolvimento livre e universal e, ao mesmo tempo, a vida de todos os indivíduos situe-se no mesmo plano de universalidade e liberdade.

\section{Referências}

CALDART, R. S. Pedagogia do Movimento Sem Terra. São Paulo: Expressão Popular, 2004.

DUARTE, N. Educação Escolar e Formação Humana omnilateral na Perspectiva da Pedagogia HistóricoCrítica. In.: LOMBARDI, J.C. (org.). Crise capitalista e educação brasileira. Uberlândia, MG : Navegando Publicações, 2016

ESCOLA NACIONAL FLORESTAN FERNANDES. Projeto Político Pedagógico da ENFF. 2016.

FREIRE, Paulo. Pedagogia do Oprimido. 49. Reimp. Rio de Janeiro: Paz e Terra, 2005.

MARX, K. Contribuição para a crítica da economia política. Lisboa: Estampa, 1973.

MARX, Karl. O capital: Crítica da economia política. 11 .ed. São Paulo. DEFEL, 1987. Livro Primeiro volume I.

MST. Dossiê MST Escola: documentos e estudos 1990-2001. Ed. especial. Caderno de educação, n.13, Iterra, 2005.

PIZETTTA, A. J. A formação política no MST: um processo em construção. Buenos Aires: Clacso, 2007.

SAVIANI, D. Escola e democracia. São Paulo: Cortez; Campinas: Autores Associados, 1984.

\section{Notas:}

${ }^{1}$ Doutorando em Educação Programa de Pós Graduação faculdade de Educação UNICAMP. Membro do Coletivo Nacional de Educação do MST. ORCID: https://orcid.org/0000-0003-3779-1056 Email: alessandromstpr@gmail.com

2 Professor Livre-Docente em Educação e Titular do DEFHE / FE / UNICAM. ORCID: http://orcid.org/0000-0001-6392$\underline{0697}$ Email: zezo@unicamp.br

3 Internacionalismo é a união internacional da classe trabalhadora para derrubar a ordem burguesa (Capitalismo) e construir uma nova forma societária (socialismo) e que foi alicerçado no Manifesto do Partido Comunista, obra de 1848, escrita por Marx e Engels. (ENFF, 2017) 